\title{
Termal Turizm Deneyiminin Müş̧teri Sadakatine Etkisinde Yaşam Kalitesi ve Müşteri Memnuniyetinin Aracı Rolü: Afyonkarahisar Örneği
}

DOI: $10.26466 /$ opus. 925920

\author{
* \\ Osman Özdemir * - Burhan Sevim ** \\ * Dr. Öğr. Üyesi, Şırnak Üniversitesi, İktisadi ve İdari Bilimler Fakültesi, Şırnak/Türkiye \\ E-Posta: osmanozdemir03@hotmail.com \\ ORCID: $\underline{0000-0001-8880-1459}$ \\ ** Doç. Dr., Kastamonu Üniversitesi, Turizm Fakültesi, Kastamonu/Türkiye \\ E-Posta: $\underline{\text { bsevim@kastamonu.edu.tr }}$ \\ ORCID: $\underline{0000-0002-3326-9642}$
}

Öz

Turizm farklı bir destinasyonu ziyaret edip orayı görmek ve orada zaman geçirmek üzerine kurulu iken günümüzde yeni bir boyut daha kazanmış ve turistlerin orada yeni deneyimler yaşamasını da içermiştir. Deneyim, turizm sektöründe eşsiz ve unutulmaz anlar yaşamak isteyen müşterilerin işletmelerden beklediği güncel bir ihtiyaç ve istek olup termal turizmde de önem arz etmektedir. Bu bağlamda işletmeler duyusal, duygusal, bilişsel, davranışsal ve ilişkisel deneyimlerden yararlanarak müşterilerine deneyim sunabilmektedir. Bu araştırmanın amacl, termal turizm deneyimi konusuna yönelik literatürdeki boşluğun doldurularak termal turizm deneyiminin müşteri sadakatine etkisini incelemektir. Ayrıca yaşam kalitesi ve müşteri memnuniyetinin aracı rolünü değerlendirmektir. Belirli bir toplumdaki bireylerin genel durumunu değerlendirmesi, yaşam kalitesini vermektedir. Duygusal olarak mutlu olma; psikolojik olarak stressiz olma; fiziksel olarak sağllklı olma; sosyal olarak aile ve arkadaşlara sahip olma; nesnel değerlendirme olarak eğitim ve gelir düzeyleri; öznel değgerlendirme olarak ise bireylerin yaşamları hakkındaki değerlendirmeleri yaşam kalitesini ortaya koymaktadır. Müşteri memnuniyeti ise işletmelerin faaliyetleri sonucu, müşterilerin yaşamına etki eden deneyimler olup onlarm kaliteli zaman geçirmesini ifade etmektedir. Afyonkarahisar ilindeki termal tesislerden turizm hizmeti almış bireylerden veriler elde edilerek AMOS paket programinda analizleri gerçekleştirilmiştir. Sonuç olarak, termal turizm deneyiminin müşteri sadakatine olumlu etkisinin olduğu; aracı değişkenlerin de bu ilişkide kısmi aracı rolünün olduğu kabul edilmiştir.

Anahtar Kelimeler: Termal Turizm Deneyimi, Yaşam Kalitesi, Memnuniyet, Sadakat. 


\title{
The Mediating Role of Quality of Life and Customer Satisfaction in the Effect of Thermal Tourism Experience on Customer Loyalty: The Case of Afyonkarahisar
}

\begin{abstract}
While tourism is based on visiting a different destination, seeing it and spending time there, it has gained a new dimension today and it is experience. Experience is a current need and demand that customers who want to live unique and unforgettable moments. It is also important for businesses in tourism sector. In this context, businesses can offer their customers experience by making use of sensory, emotional, cognitive, behavioral and relational experiences. The purpose of this research is to examine the effect of thermal experience on customer loyalty. It also focuses on the mediating role of quality of life and customer satisfaction. Quality of life is individuals' evaluations about their lives reveal the quality of life. Customer satisfaction, on the other hand, is the experience that affects the lives of the customers as a result of the activities of the businesses and refers to their quality time. Data were obtained from individuals who received tourism services from thermal facilities in Afyonkarahisar and analyzed in the AMOS package program. As a result, the effect of thermal experience on customer loyalty and the partial effect of mediator variables are accepted.
\end{abstract}

Keywords: Thermal Experience, Quality of Life, Satisfaction, Loyalty. 


\section{Giriş}

Dünyada termal turizm sektörü önemli bir ivme kazanmış olup bu alanda yatırımlar almaya devam etmektedir. Türkiye'de ise Afyonkarahisar ili (Sandıklı, Bolvadin ve İhsaniye ilçeleri ile birlikte) termal turizm bağlamında en önemli destinasyonlardan birisi durumuna gelmiş olup 29 işletme belgeli ve 7 yatırım belgeli tesisi ile turistlere termal turizm imkânı sunmaktadır. Kültür ve Turizm Bakanlığı'nın Aralık-2020 konaklama tesisi verilerine göre Türkiye'nin 15. büyük turizm şehridir (YİGM, 2020). Bu çalışmada termal turizm deneyimi ile yaşam kalitesi, müşteri memnuniyeti ve sadakati arasındaki ilişki Afyonkarahisar özelinde incelenmiş ve termal turizm deneyimi konusuna yönelik literatürdeki boşluk doldurulmuştur.

\section{Termal Turizm Deneyimi}

Hizmet sektörünün önemli bir unsuru olan turizm, tüketicilerin ihtiyaç ve isteklerine göre çeşitlenebilmektedir. Turizm sektöründe genel olarak bir pazarlama stratejisi olarak kitle turizm önerilse de bilgi toplumunun gelişmesi ve taleplerinin çeşitlenmesi ile (Stamboulis ve Skayannes, 2003, s.35) termal turizme ve termal turizm deneyimine ilgi artmıştır.

Turizm farklı bir destinasyonu ziyaret edip orayı görmek ve orada zaman geçirmek üzerine kurulu iken günümüzde yeni bir boyut daha kazanmış ve turistlerin orada yeni deneyimler yaşamasını da içermiştir. Bu nedenle bir destinasyonda yeni deneyimlerin tasarlanması, maliyetinin hesaplanması, fiyatlandırılması ve sunulması stratejik önem ifade etmektedir (Pine ve Gilmore, 1999; Stamboulis ve Skayannes, 2003, s.38).

Turizm deneyimi farklı temellere dayanabilmektedir. Gastronomi menülü restoranlar, festivaller, yerel imalathaneler, müzikal ve kültürel performanslar, tema parklar, sanat galerileri, müzeler, alışveriş merkezleri, bilim merkezleri, teleferik, dalış, tırmanma, kamp aktiviteleri, spor etkinlikleri, dağ bisikleti turları ve safariler farklı turizm deneyimlerine örnek oluşturmaktadır (Garnier ve Scott, 2018, s.126). Termal turizm faaliyeti de her şehir veya otelde olmadığ için bir deneyim olarak ifade edilebilmekte olup 21. yüzyılda modern dünyanın olumsuz etkilerinden kurtulmak isteyen bireylerin tercih ettiği bir turizm türüdür (Luo vd., 2018). 
Deneyim, turizm sektöründe eşsiz ve unutulmaz anlar yaşamak isteyen müşterilerin işletmelerden beklediği güncel bir ihtiyaç ve istek olup termal turizmde de önem arz etmektedir. Kırsal turizm, şarap turizmi, çarter turizm, dügün turizmi vb. gibi farklı turizm türlerinde de deneyimin etkisi kanitlanmıştır (Luo vd., 2018).

Pazarlamada emtia, mal ve hizmet yerini günümüzde deneyime bırakmıştır (Pine ve Gilmore, 1999). Bu bağlamda çalışan ve müşteri arasındaki etkileşime dayanan hizmet, müşterinin süreçte aktif olarak yer aldığı ve deneyim olarak ifade edilen yeni bir yaklaşıma yerini bırakmıştır. Hizmet çalışan ve müşterinin birlikte üretmesine dayanırken, deneyim mutluluk, üzüntü, korku, öfke, utanma vb. duyguların sadece müşteri tarafından hissedildiği bir sürece dayanmaktadır (Johnson ve Kong, 2011). Turizm sektöründe -özellikle termal turizmde- fiziksel ve psikolojik olarak sağllğına kavuşmak için turistler termal destinasyonlara yönelmektedir.

Deneyim ekonomisi (Pine ve Gilmore, 1999), deneyimsel pazarlama (Schmitt, 1999), müşteri deneyimini yönetme (Smith ve Wheeler, 2002) ve müşteri deneyimi inşası (Shaw - Iwens, 2002) vb. çalışmalar bu alanda yapılan ilk çalışmalardır. Turizm bağlamında değerlendirildiğinde ise $\mathrm{Oh}$ (2007), Johnston ve Kong (2011), Kim vd. (2015), Tokarchuk vd. (2015), Luo vd. (2018) ve Campón-Cerro vd. (2020)'nin çalışmaları turizm deneyimine odaklanarak bu çalışmanın kavramsal alt yapısını oluşturmaktadır.

İşletmeler duyusal, duygusal, bilişsel, davranışsal ve ilişkisel deneyimlerden yararlanarak müşterilerine deneyim sunabilmektedir (Schmitt, 1999, s.60). Duyusal deneyim müşterilerin beş duyu organına; duygusal deneyim müşterilerin iç dünyasına; bilişsel deneyim müşterilerin akılcı değerlendirmelerine; davranışsal deneyim müşterilerin hayat tarzlarını değiştirerek belirli bir davranışa yönelmelerine; ilişkisel deneyim ise müşterilerin alt kültür oluşturarak marka toplulukları haline gelmesine dayanmaktadır (Özdemir ve Erdem, 2017).

Müşteri deneyimi eğlence, eğitim, gerçeklikten kaçış ve estetik bağlamında değerlendirilmektedir (Pine ve Gilmore, 1999). Ayrıca turistler deneyime katılım ve çevresel ilişkileri bağlamında da değerlendirilebilmektedir. Turistlerin deneyimde aktif olarak yer alması veya pasif olarak izleyici konumunda olması söz konusu olabilmektedir. Turistlerin deneyimde çevresel ilişkileri ise güçlü veya zayıf olabilmektedir. Bu bağlamda turizm 
deneyimi eğlence, eğitim, gerçeklikten kaçış ve estetik bağlamında değerlendirilmekte olup Şekil 1'de gösterilmiştir. Buna göre (Pine ve Gilmore, 1999, s.102; Stamboulis ve Skayannes, 2003, s.35; Tümer Karadayı ve Koçak Alan, 2014, s.207);

- $\quad$ Eğlence deneyimi, turistlerin müzik festivalleri vb. gibi aktivitelere pasif katılımları ile gerçekleşmekte ve zayıf bir çevresel ilişkiye dayanmaktadir.

- $\quad$ Eğitim deneyimi, turistlerin ders vb. gibi aktivitelere aktif katılımları ile gerçekleşmekte ve zayıf bir çevresel ilişkiye dayanmaktadır. Eğitim deneyimine örnek olarak rafting eğitimi alan turistler verilebilmektedir.

- $\quad$ Gerçeklikten kaçış deneyimi, turistlerin deneyime aktif katılımları ile gerçekleşmekte ve güçlü bir çevresel ilişkiye dayanmaktadır. Gerçeklikten kaçış deneyimine örnek olarak kayak yapan turistler verilebilmektedir.

- $\quad$ Estetik deneyimi ise turistlerin sergi vb. aktivitelere pasif katılımları ile gerçekleşmekte ve güçlü bir çevresel ilişkiye dayanmaktadır.

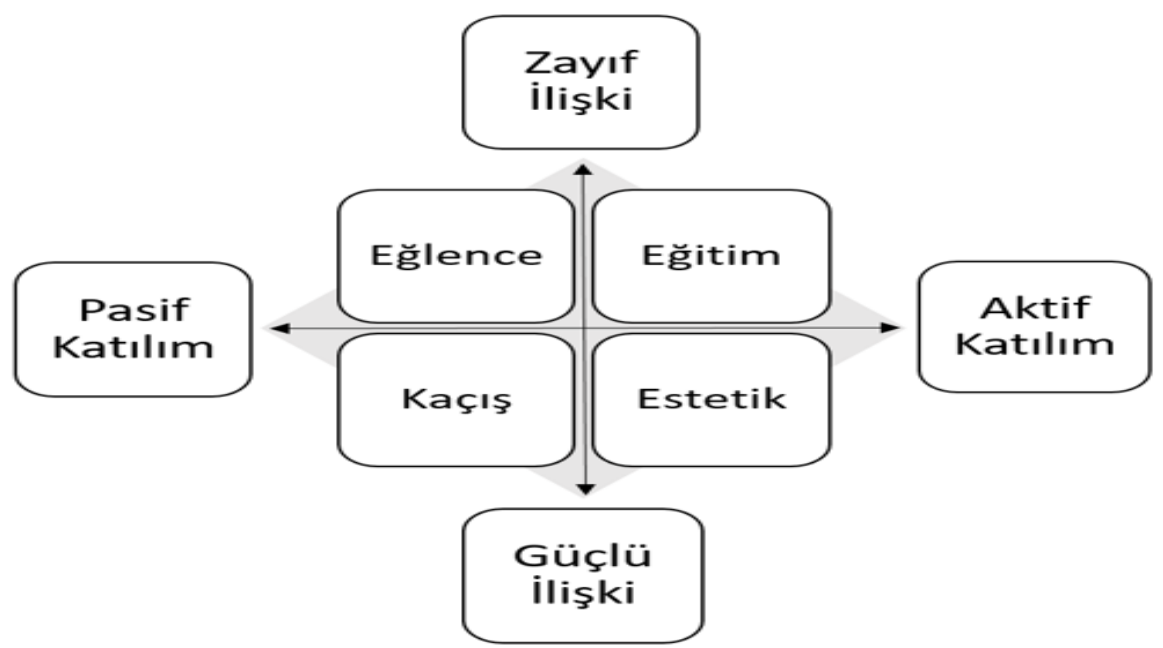

Şekil 1. Deneyimin Katılım ve İlişki Boyutu (Pine ve Gilmore, 1999, s.117)

Deneyimin önemine yönelik öznel iyi oluş teorisinde değinilmekte olup önyargıların deneyim öncesinde müşterilerin beklentisi ve değerlendirmesine; deneyim sonrasinda ise duygu ve düşüncelerine etkisinin olduğu ifade edilmektedir. 


\section{Yaşam Kalitesi}

Belirli bir toplumdaki bireylerin olumlu olarak değerlendirdiği genel durumu ifade eden yaşam kalitesi, duygusal olarak mutlu olma; psikolojik olarak stressiz olma; fiziksel olarak sağlıklı olma; sosyal olarak aile ve arkadaşlara sahip olma; nesnel değerlendirme olarak eğitim ve gelir düzeyleri; öznel değerlendirme olarak ise bireylerin yaşamları hakkındaki değerlendirmeleri yaşam kalitesini ortaya koymaktadır (Luo vd., 2018). Bu bağlamda turizm sektöründe de yaşam kalitesi müşterilerin deneyimlerine dayanmaktadir.

Turizm -özellikle termal turizm- müşterilere belirli faydalar sağlayarak onların yaşam kalitelerini artırmaktadır (Chen ve Petrick, 2013, s.709-719). Müşterilerin psikolojik ve fizyolojik refahını artırmak bu faydaların başında gelmektedir. Ayrıca destinasyonlar yedi farklı deneyime göre değerlendirilebilmektedir. Destinasyonların kendisine özgü yapısı, işlevsel, hedonik, ekonomik, güvenlik ve ahlaki durumları ile boş zaman aktiviteleri destinasyonlar hakkında belirleyici olmakla birlikte müşterilerin yaşam kalitelerini de etkilemektedir (Tokarchuk vd., 2015, s.599).

Yaşam kalitesi, bireylerin yaşının ilerlemesiyle birlikte düşmektedir. Psikolojik, sosyolojik ve gerontolojik (yaşlllik bilimi) olarak bireylerin refah ve mutluluğu yaşam kalitesine bağlı bulunmaktadır. Diğer taraftan 2050 yılına gelindiğinde 65 yaş üzeri bireylerin dünya nüfusunun $\% 26^{\prime} \sin 1$ oluşturacağı öngörülmektedir. Bu nedenle turizm sektöründe potansiyeli yüksek bir pazar olarak ileri yaşlı bireylere odaklanılmaktadır (Kim vd., 2015, s.465-467). Yaşam kalitesini artırmak isteyen ileri yaşlı bireylerin -aktivite teorisinde belirtildiği gibi- emeklilik nedeniyle boş zamanlarının fazla olması, sağlıkları için termal turizmine yönelmesi ve sunulan hizmetleri satın alma gücüne sahip olması işletmelerin bunu bir firsat olarak görüp bu alana yatırım yapmasına neden olmaktadır (Sirgy vd., 2012, s.261).

\section{Müşteri Memnuniyeti}

Müşteri deneyiminin bir sonucu olan memnuniyet, turizm sektöründe işletmelerin amacı olarak görülmektedir (Luo vd., 2018). Literatürde müşterilerin yaşamına etki eden deneyimler olarak tanımlanan memnuniyet, müşterinin kaliteli zaman geçirmesini ifade etmektedir. Bu bağlamda müşterinin işletme 
ve hizmetlerine yönelik fayda-maliyet hesabı yaparak memnuniyetini ve memnuniyetsizliğini değerlendirmesidir (Sirgy vd., 2012, s.263; Durmuş, Tanrısever ve Pamukçu, 2020, s.360).

Psikoloji alanında sıkça çalışılan bir kavram olan memnuniyet, bireylerin duygusal durumlarına dayanmakta olup bireyin aile, çevre, din, iş ve aşk dahil olmak üzere birçok durumundan etkilemektedir (Luo vd., 2018). Turizm alanında memnuniyet, müşterilerin hedonik deneyimlerine, ekonomik olarak güç yetirebilmelerine, destinasyona yönelik sağlık, güvenlik ve ahlaki algilarına göre değişebilmektedir (Tokarchuk vd., 2015, s.600). Termal turizmde ise memnuniyet, müşterilerin yaşına, yaşam dönemine ve sağlık durumuna göre değişebilmektedir (Garnier ve Scott, 2018, s.130).

Müşterilerin memnuniyeti birbirinden farklılık gösterebilmektedir. Çünkü her müşterinin katlandığı zaman, maliyet ve çaba eşit değildir. Bu bağlamda eşitlik teorisinin önemi ortaya çıkmakta olup müşterilerin beklentilerinin karşılanması gerekmektedir. Hatta sunulan deneyimlerin beklentileri aşması ile müşteri sadakatinin oluşacağı da öngörülmektedir (Mechinda, Serirat ve Gulid, 2009, s.132).

\section{Müşteri Sadakati}

Turizm sektöründe sadakat, işletmelerin sürdürülebilir büyümelerini sağlamakta olup işletmelerin müşterilerde sadakati oluşturması gerekmektedir. $\mathrm{Bu}$ bağlamda işletmeler müşterilerden geri bildirim alarak onlarda katılım duygusu oluşturabilmekte ve aidiyet duygusu sağlayabilmektedir. Diğer taraftan işletme ve müşterileri arasında günümüzde etkileşim artmakta ve sadakat oluşmaktadır (Stamboulis ve Skayannes, 2003, s.41). Termal turizm sektöründe de hem termal şehirler hem de termal oteller arasında rekabet devam etmektedir ve sadakatin önemi bu rekabette anlaşılmaktadır. Sadık müşterilerin pazarlama ve tutundurma maliyetleri düşük seviyede olup ağızdan ağıza iletişim ile işletmelere yeni müşteri sağlama potansiyelleri de onları değerli kılmaktadır.

Termal turizm, müşterilerin sağlık durumlarını iyileştirmek amacıyla tercih ettiği ve bu nedenle sadakat duyduğu bir turizm türüdür. Düşük gelirli, kronik rahatsızlıkları bulunan veya dezavantajlı bireyler de dahil olmak üzere toplumun her kesiminden çalışan ve emekli müşteriler termal turiz- 
mden yararlanmaktadır (Chen ve Petrick, 2013, s.709-719). Ayrica termal turizmde destinasyonun lokasyonu önemli olup müşterinin destinasyona ulaşmak için sarf ettiği çaba, harcadığı zaman ile katlandığı maliyet müşterinin refah düzeyini belirlemektedir. Bu nedenle, destinasyonun yakın olması veya ulaşım alt yapısının bulunması önem arz etmektedir (Tokarchuk vd., 2015, s.603).

Müşteri sadakatinin oluşmasının belirli nedenleri bulunmaktadır. Memnuniyet, geçmiş deneyimler, düşük maliyet ve duygusal bağ müşterilerde motivasyon oluşturmaktadır. Bu bağlamda itme ve çekme motivasyonun termal turizme yönelik sadakatte etkisinden söz edilebilmektedir. Afyonkarahisar şehri deneyim, yenilik, rahatlık sunması ve aile bağlarına uygun olması ile itme motivasyonu; tarihi, kaliteli hizmeti, alışveriş imkanları, gastronomisi ve manzaraları ile çekme motivasyonu ve dolayısıyla müşteri sadakati oluşturmaktadır (Mechinda vd., 2009, s.141).

Bu bağlamda termal turizm deneyimi, yaşam kalitesi, müşteri memnuniyeti ve sadakati arasındaki ilişkiler değerlendirilmiş olup (Johnson ve Kong, 2011; Sirgy, Kruger, Lee ve Yu, 2012, s.262) aşağıdaki hipotezler oluşturulmuştur.

H1: Termal turizm deneyiminin yaşam kalitesine etkisi bulunmaktadır.

H2: Termal turizm deneyiminin müşteri memnuniyetine etkisi bulunmaktadır.

H3: Termal turizm deneyiminin müşteri sadakatine etkisi bulunmaktadır.

H4: Yaşam kalitesinin müşteri sadakatine etkisi bulunmaktadır.

H5: Termal turizm deneyiminin müşteri sadakatine etkisinde yaşam kalitesinin aracı rolü vardır.

H6: Müşteri memnuniyetinin müşteri sadakatine etkisi bulunmaktadır.

H7: Termal turizm deneyiminin müşteri sadakatine etkisinde müşteri memnuniyetinin aracı rolü vardır.

\section{Yöntem}

\section{Araştırmanın Amacı, Soruları ve Anakütlesi}

Termal turizm sektöründe işletmeler, müşterilerine deneyim yaşatarak karlarını ve sürdürülebilir büyümelerini artırmayı hedeflemektedir. Bu 
bağlamda araştırmanın amacı, termal turizm deneyiminin müşteri sadakatine etkisini incelemek olup yaşam kalitesi ve müşteri memnuniyetinin aracı rolünü de değerlendirmektir.

Araştırmanın soruları "Termal turizm deneyiminin müşteri sadakati üzerinde etkisi var mıdır?" ve "Yaşam kalitesi ve müşteri memnuniyetinin termal turizm deneyimi ve müşteri sadakati ilişkisinde aracı rolü var mıdır?" şeklinde oluşturulmuştur.

Araştırmanın anakütlesini Afyonkarahisar ilindeki termal tesislerden turizm hizmeti almış bireyler oluşturmakta olup anket çalışmasına online olarak katılan 216 birey ise araştırmanın örneklemini oluşturmaktadır.

\section{Araştırmanın Modeli, Yöntemi ve Ölçekleri}

Termal turizm deneyiminin müşsteri sadakatine etkisini inceleyen bu çalışmada; termal turizm deneyimi bağımsız değişken, müşteri sadakati bağımlı değişken, yaşam kalitesi ve müşteri memnuniyeti ise aracı değişkenler olarak modelde yer almaktadır. Araştırmada öncelikle detaylı bir literatür taraması ve akademisyenler ile görüşmeler gerçekleştirilmiş olup araştırmanın modeline uygun bir anket formu hazırlanmıştır. Şırnak Üniversitesi Etik Kurulu Başkanlığı'nın 31.12.2020 tarih ve 2020/69 sayılı kararı sonucuna göre anket formunun etik yönden uygun bulunması ile 1-31 Ocak 2021 tarihleri arasında araştırma verileri online olarak toplanmıştır. Sonrasında ise Excel, SPSS 23.0 ve AMOS 22.0 paket programları kullanılarak nicel analizler gerçekleştirilmiştir.

Araştırmada kullanılan termal turizm deneyimi ölçeği için Luo vd. (2018)'nin çalı̧̧masından; yaşam kalitesi ölçeği için Campón-Cerro vd. (2020)'nin çalışmasından; müşteri memnuniyeti ölçeği için Durmuş vd. (2020)'nin çalışmasından; müşteri sadakati ölçeği için ise Mechinda vd. (2009)'nin çalışmasından yararlanılmıştır. 


\section{Bulgular}

\section{Demografik Bulgular}

Tablo 1. Demografik Bulgular

\begin{tabular}{llllllll}
\hline \multicolumn{2}{l}{ Demografik Profil } & Fr. & $\mathbf{\%}$ & \multicolumn{2}{l}{ Demografik Profil } & Fr. & $\%$ \\
\hline Cinsiyet & Kadın & 127 & 58.8 & Medeni & Evli & 76 & 35.2 \\
& Erkek & 89 & 41.2 & Durum & Bekar & 140 & 64.8 \\
\hline Yaş & 25 ve altı & 30 & 13.9 & Eğitim & İlköğretim & 18 & 8.3 \\
& $26-35$ & 121 & 56.0 & Durumu & Lise & 30 & 13.9 \\
& $36-45$ & 42 & 19.4 & & Ön Lisans & 24 & 11.1 \\
& $46-55$ & 16 & 7.4 & & Lisans & 89 & 41.2 \\
& $56-65$ & 7 & 3.2 & & Yüksek Lisans & 37 & 17.1 \\
& & & & & Doktora & 18 & 8.3 \\
\hline Meslek & Kamu Sektörü & 76 & 35.2 & Gelir & 2500 TL ve altı & 61 & 28.2 \\
& Özel Sektör & 64 & 29.6 & & 2501-5000 TL & 78 & 36.1 \\
& Öğrenci & 20 & 9.3 & & 5001-7500 TL & 40 & 18.5 \\
& Emekli & 4 & 1.9 & & $7501-10.000 \mathrm{TL}$ & 28 & 13.0 \\
& Çalısmiyor & 52 & 24.1 & & 10.000 TL üstü & 9 & 4.2 \\
\hline
\end{tabular}

Araştırmada katılımcı olarak yer alan 216 kişiye ait demografik bulgular tabloda gösterilmekte olup cinsiyete göre kadınların, medeni duruma göre bekarların, yaşa göre 26-35 yaş aralığında olanların, eğitim durumuna göre ise lisans mezunlarının ağırlıklı olduğu görülmektedir. Çalışılan sektör açısından kamu sektöründe ve özel sektörde çalışanların; gelir açısından ise 5000 TL ve altında gelire sahip olanların fazla olduğu görülmektedir.

\section{Doğrulayıcı Faktör Analizi}

Araştırma, termal turizm deneyimi, yaşam kalitesi, müşteri memnuniyeti ve sadakati arasındaki ilişkiyi açıklamak için yapılandırılmıştır. Ölçeklerin temel yapısını belirlemek ve faktörlerin geçerliliğini doğrulamak için doğrulayıc faktör analizi yapılmıştır. Ki-kare testi istatistikleri genel olarak örneklem büyüklüğüne oldukça duyarlı olup (Hair, Black, Babin, Anderson ve Tatham, 2006) bu araştırmada; Uyum İyiliğgi İndeksi (GFI), Karşılaştırmalı Uyum İndeksi (CFI), Normlaştırılmış Uyum İndeksi (NFI), Tucker Lewis İndeksi (TLI) ve Kök Ortalama Kare Hata Yaklaşımı (RMSEA) dikkate alınmıştır. Ayrıca, verilerin uygunluğunu test etmek için Kaiser-Meyer-Olkin 
(KMO) örnekleme yeterliliği ve Bartlett küresellik testleri uygulanmıştır (Sharma, 1996).

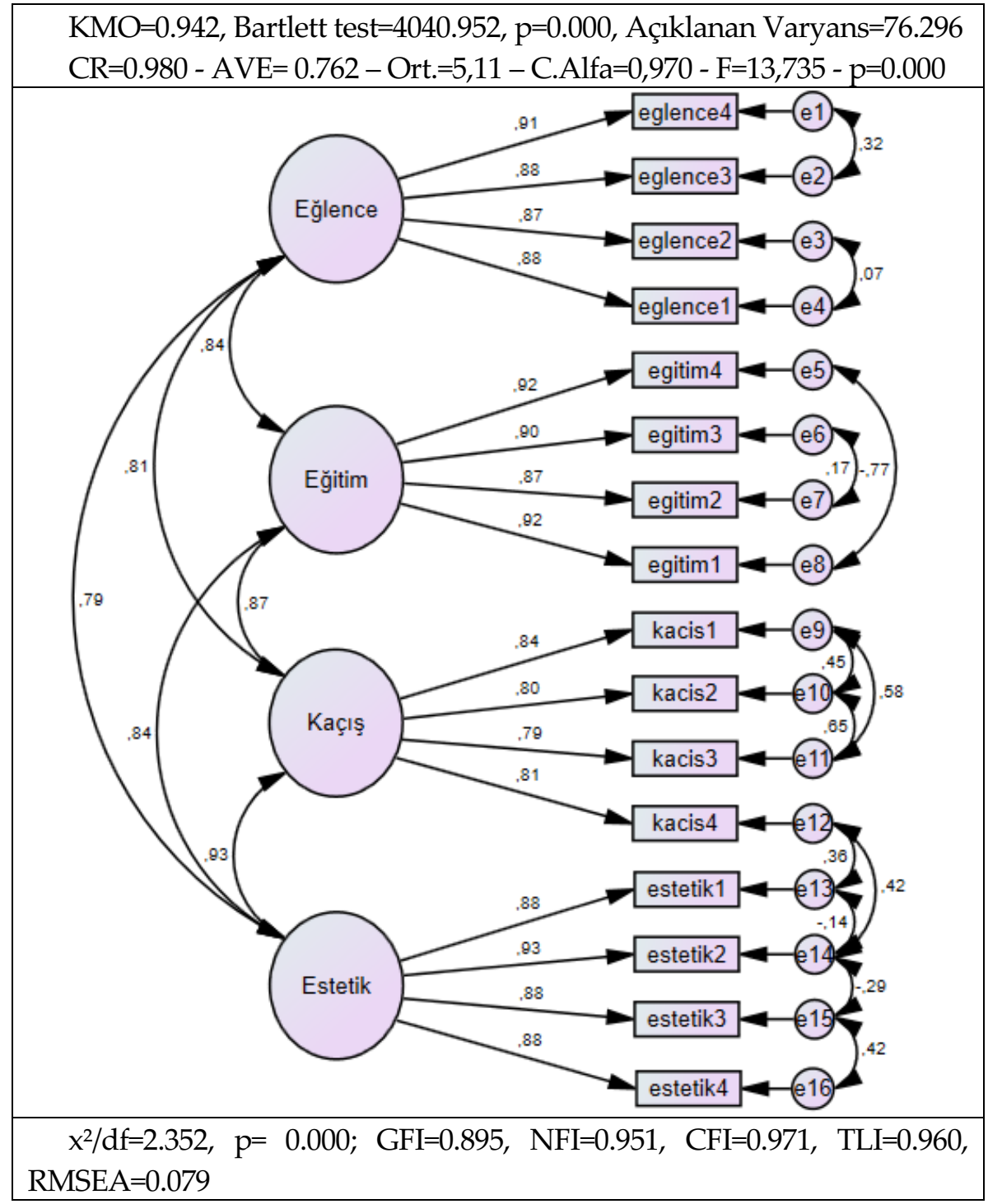

Şekil 2. Termal Turizm Deneyimine Ait Doğrulayıcı Faktör Analizi 
Termal turizm deneyimine yönelik doğrulayıcı faktör analizi sonuçlarına göre GFI değeri hariç tüm değerlerin kabul edilebilir sınırlar içerisinde olduğu görülmektedir. KMO ve Cronbach Alfa değerlerinin 1'e yakın olmas1; $C R$ değerinin 0,70 'den ve AVE değerinin 0,50 'den büyük olmasl; uyum endeks değerlerinin 0,90 'den büyük olması; RMSEA değerinin $0,08^{\prime}$ den az olması modelin güvenilir, geçerli ve anlamlı olduğunu göstermektedir. Diğer taraftan GFI değerinin 0,90'dan az $(0,895)$ olmasındaki sebep, bu değerin örneklem sayısından etkilenmesidir.

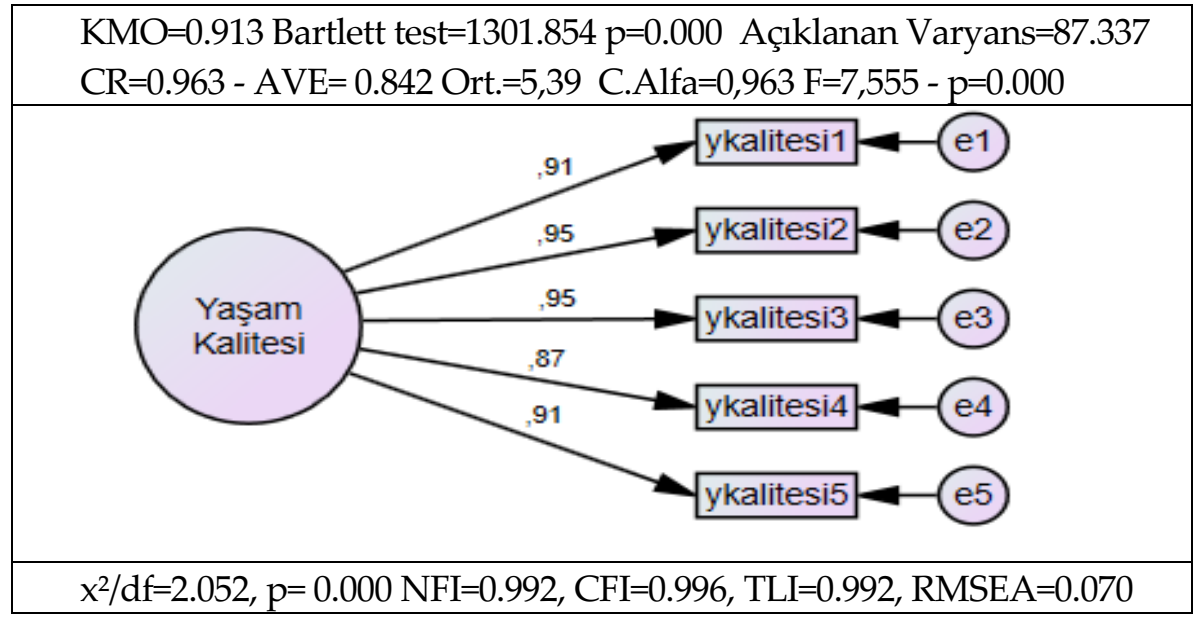

Şekil 3. Yaşam Kalitesine Ait Doğrulayıcı Faktör Analizi

Yaşam kalitesine yönelik doğrulayıcı faktör analizi sonuçlarına göre KMO ve Cronbach Alfa değerlerinin 1'e yakın; $C R$ değerinin 0,70'den ve AVE değerinin 0,50'den büyük; uyum endeks değerlerinin 0,90'den büyük; RMSEA değerinin de $0,08^{\prime}$ den az olması modelin güvenilir, geçerli ve anlamlı olduğunu göstermektedir. 


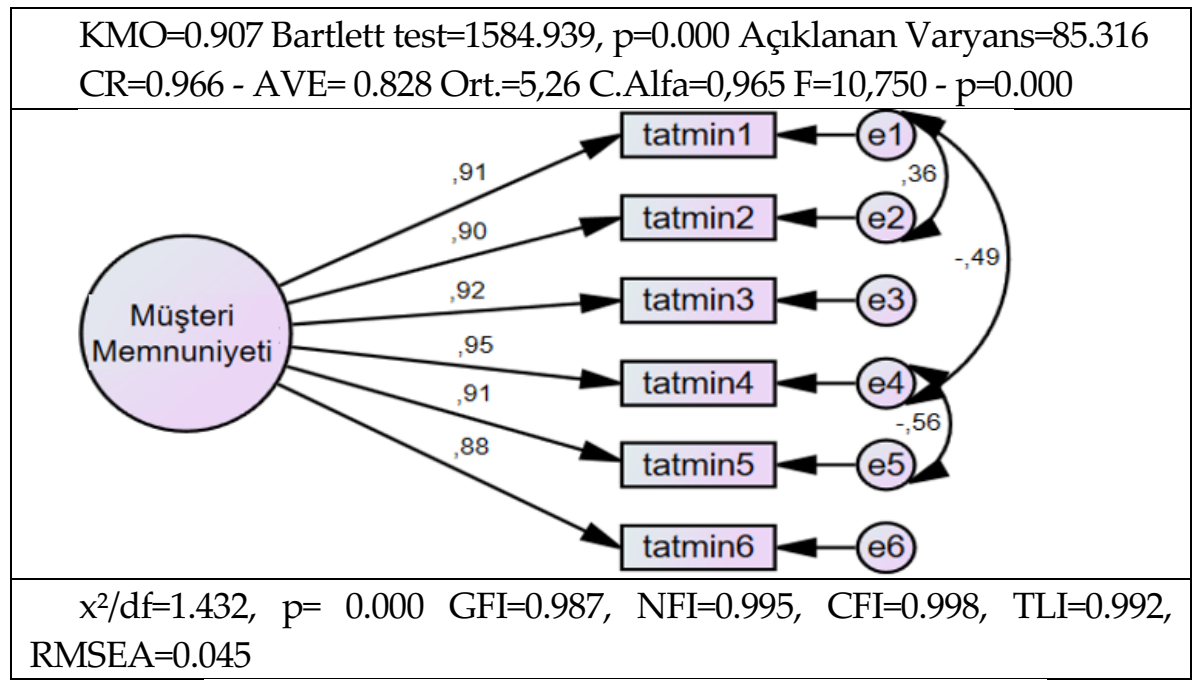

Şekil 4. Müşteri Memnuniyetine Ait Doğrulayıcı Faktör Analizi

Müşteri memnuniyetine yönelik doğrulayıcı faktör analizi sonuçlarına göre $\mathrm{KMO}$ ve Cronbach Alfa değerlerinin 1'e yakın olması; CR değerinin 0,70'den ve AVE değerinin 0,50'den büyük olması; uyum endeks değerlerinin $0,90^{\prime}$ den büyük olması; RMSEA değerinin $0,08^{\prime}$ den az olması modelin güvenilir, geçerli ve anlamlı olduğunu göstermektedir.

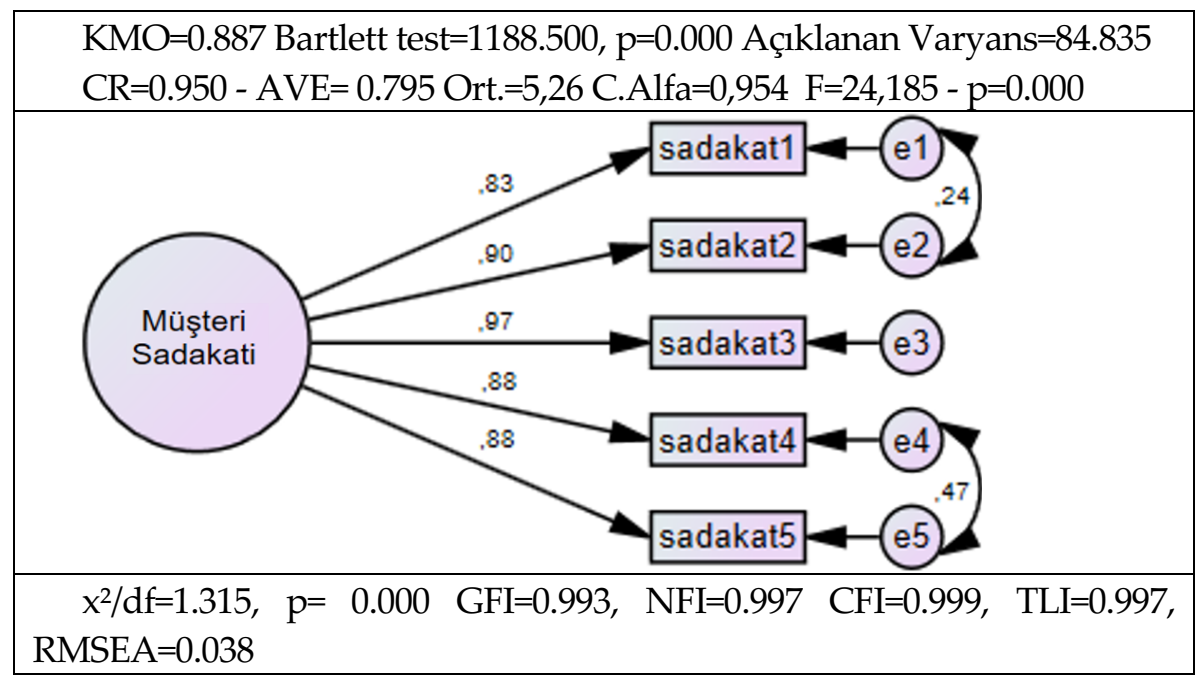

Şekil 5. Müşteri Sadakatine Ait Doğrulayıcı Faktör Analizi 
Müşteri sadakatine yönelik doğrulayıcı faktör analizi sonuçlarına göre KMO ve Cronbach Alfa değerlerinin 1'e yakın olması; CR değerinin 0,70'den ve AVE değerinin 0,50'den büyük olmasl; uyum endeks değerlerinin 0,90 ' den büyük olması; RMSEA değerinin 0,08 ' den az olması modelin güvenilir, geçerli ve anlamlı olduğunu göstermektedir.

Sonuç olarak her faktör için Cronbach Alfa değeri 0,7'den büyük olarak belirlenmiştir. Cronbach Alfa değerinin 0,7'den büyük olması, kullanılan ölçeğin iç tutarlılığının yeterli düzeyde olduğunu göstermektedir (Tavakol ve Dennick, 2011). Ayrıca ölçeğin geçerliliğini test etmek için AVE ve CR değerleri de faktör bazında hesaplanmıştır. $C R$ değerleri 0,70 değerinden ve AVE değerleri de 0,50 değerinden büyüktür. Bu bağlamda ölçeklerin geçerli olduğu da anlaşılmıştır.

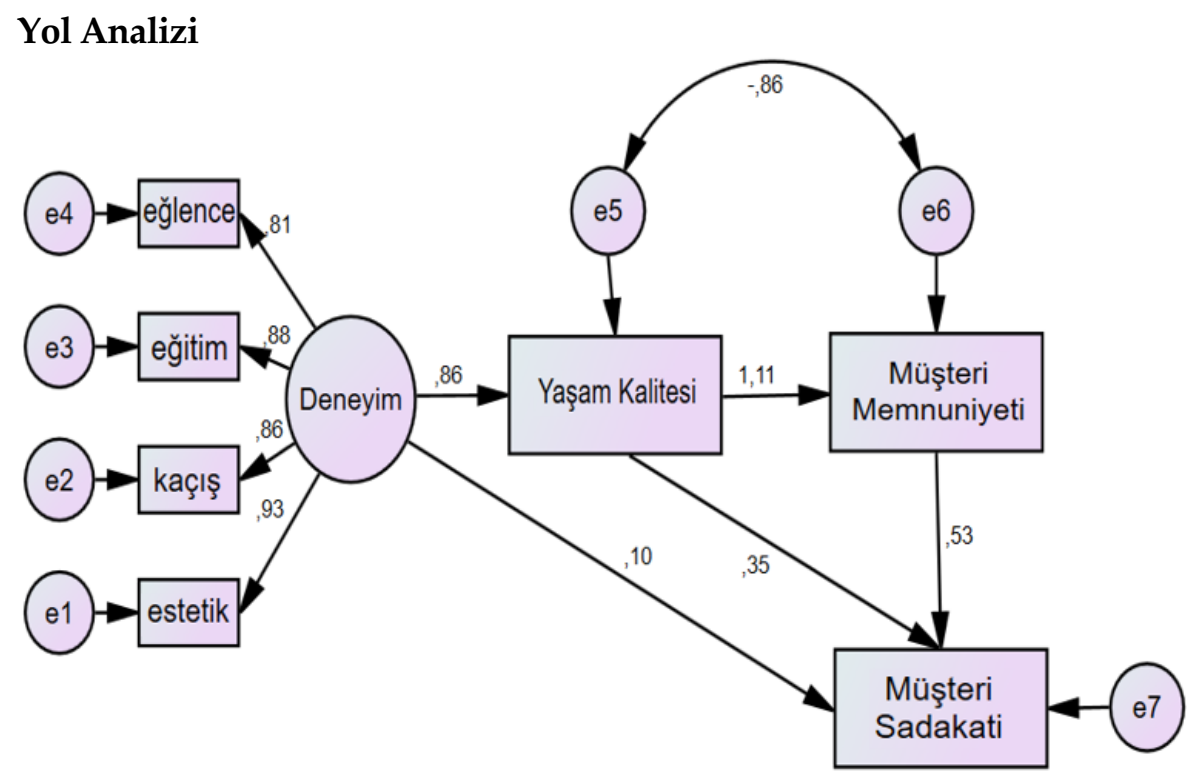

Şekil 6. Yol Analizi Sonucu

Şekil 6'daki yol analizi incelendiğinde yaşam kalitesi ve memnuniyet arasında kovaryans olduğu görülmektedir. Literatürde bu kovaryansı destekleyen çalışmalar olduğu; yaşam kalitesi ve müşteri memnuniyetinin birbirine yakın kavramlar olduğu; hatta çalışmalarda birbirinin yerine kullanıldığı da görülmüştür. 
Tablo 2. Yol Analizi Sonuçlarının Uyum Değerleri ile Karşılaştırılması

\begin{tabular}{|c|c|c|c|}
\hline Uyum & İyi & Kabul Edilebilir & Model \\
\hline Ölçütü & Uyum & Uyum & Sonucu \\
\hline $\mathrm{x}^{2} / \mathrm{df}$ & $0 \leq x^{2} / \mathrm{df} \leq 2$ & $2 \leq \mathrm{x}^{2} / \mathrm{df} \leq 5$ & 2,229 \\
\hline RMSEA & $0 \leq \mathrm{RMSEA} \leq 0,05$ & $0,05 \leq$ RMSEA $\leq 0,08$ & 0.076 \\
\hline GFI & $0,95 \leq \mathrm{GFI}<1$ & $0,90 \leq \mathrm{GFI} \leq 0,95$ & 0.967 \\
\hline NFI & $0,95 \leq \mathrm{NFI}<1$ & $0,90 \leq \mathrm{NFI} \leq 0,95$ & 0.988 \\
\hline CFI & $0,95 \leq \mathrm{CFI}<1$ & $0,90 \leq \mathrm{CFI} \leq 0,95$ & 0.993 \\
\hline TLI & $0,95 \leq \mathrm{GFI}<1$ & $0,90 \leq \mathrm{GFI} \leq 0,95$ & 0.987 \\
\hline
\end{tabular}

Yol analizi sonucunda öncelikle modelin anlamlılığı ki-kare ve RMSEA değerleri ile incelenmiştir. Termal turizm deneyiminin müşteri sadakatine etkisinde yaşam kalitesi ve müşteri memnuniyetinin aracı rolü ise yol analizindeki uyum endeks değerleri ile ortaya konmuştur. Modeldeki değerlerin kabul edilebilir aralıkta olduğu; bu bağlamda aracılık etkisinin olduğu anlaşılmıştır.

\section{Hipotez Sonuçları}

Tablo 3. Hipotez Sonuçlan

\begin{tabular}{|c|c|c|c|c|c|c|}
\hline \multirow[t]{2}{*}{ Hipotezler } & \multirow[t]{2}{*}{$\mathbf{R}$} & \multirow[t]{2}{*}{$\mathbf{R}^{2}$} & $\mathbf{F}$ & \multirow[t]{2}{*}{ B } & $\mathbf{t}$ & \multirow[t]{2}{*}{ Sonu } \\
\hline & & & p & & $\underline{p}$ & \\
\hline \multirow[t]{2}{*}{ Deneyim $\rightarrow$ Yaşam Kalitesi } & $0,906^{\mathrm{a}}$ & 0,670 & 437,440 & 0,819 & 20,915 & Kabul \\
\hline & & & ,000 & & ,000 & \\
\hline \multirow[t]{2}{*}{ Deneyim $\rightarrow$ M. Memnuniyeti } & $0,937^{a}$ & 0,837 & 1103,437 & 0,915 & 33,218 & Kabul \\
\hline & & & ,000 & &, 000 & \\
\hline \multirow[t]{2}{*}{ Deneyim $\rightarrow$ M. Sadakati } & $0,868^{\mathrm{a}}$ & 0,753 & 652,971 & 0,868 & 25,553 & Kabul \\
\hline & & & ,000 & & ,000 & \\
\hline \multirow[t]{2}{*}{ Yaşam Kalitesi $\rightarrow$ M.Sadakati } & $0,906^{\mathrm{a}}$ & 0,821 & 984,571 & 0,906 & 31,378 & Kabul \\
\hline & & & ,000 & &, 000 & \\
\hline \multirow[t]{2}{*}{ Memnuniyet $\rightarrow$ M. Sadakati } & $0,937^{a}$ & 0,877 & 1540,384 & 0,937 & 39,248 & Kabul \\
\hline & & & ,000 & & ,000 & \\
\hline
\end{tabular}

Hipotezleri test etmek amaciyla öncelikle Basit Regresyon Analizleri gerçekleştirilmiştir. Anlamlılık değerlerinin 0,05’ten az $(p=0,000<0,05)$ olması sonucuna dayanarak hipotezler kabul edilmiştir. Sonrasında ise SPSS paket programındaki Hayes süreç uzantısı ile aracı etki analizleri gerçekleştirilmiştir. 
Tablo 4. Aracılık Etkisine Yönelik Hipotez Sonuçlan

\begin{tabular}{llllllll}
\hline Hipotezler & Beta & se & LLCI & ULCI & $\mathbf{t}$ & $\begin{array}{l}\mathbf{R}^{2} \\
\mathbf{p}\end{array}$ & Sonuç \\
& & & & & $\mathbf{p}$ & \\
\hline Deneyim $\rightarrow$ Sadakat & $\mathbf{0 , 9 2 2}$ & 0,036 & 0,8511 & 0,9933 & 25,5533 & $\mathbf{0 , 7 5 3}$ & Kabul \\
& & & & &, 000 &, 000 & \\
D. $\rightarrow$ Y. K. $\rightarrow$ S. & $\mathbf{0 , 3 5 7}$ & 0,046 & 0,2658 & 0,4482 & $\begin{array}{l}7,7171 \\
0,905\end{array}$ & Kabul \\
& & & & &, 000 &, 000 & \\
D. $\rightarrow$ M. M. $\rightarrow$ S. & $\mathbf{0 , 5 9 0}$ & 0,065 & 0,4613 & 0,7202 & $\begin{array}{l}8,9948 \\
0,905\end{array}$ & Kabul \\
& & & & &, 000 &, 000 & \\
\hline
\end{tabular}

Aracılık modelinin test edilmesinde geçerli olan koşullara göre deneyimin müşteri sadakatine pozitif yönde ve anlamlı düzeyde etkisinin bulunduğu görülmektedir $(\mathrm{p}=0,000<0,05)$. Deneyimin aracı değişkenler olan yaşam kalitesi ve müşteri memnuniyetine pozitif yönde ve anlamlı düzeyde etkisinin bulunduğu da görülmektedir $(p=0,000<0,05)$. Deneyimin müşteri sadakati üzerindeki etkisinde yaşam kalitesi ve müşteri memnuniyetinin kısmi aracılık rolünün olduğu ise Tablo 4 'teki değerlerden Beta değerindeki değişimlerden anlaşılmaktadır. Aracılık etkisi ile Beta değerleri (Beta=0,357 < Beta $=0,922) \quad($ Beta $=0,590<$ Beta $=0,922)$ azalmış olup hipotezler kabul edilmiştir.

\section{Sonuç}

Termal turizm, müşterilere belirli faydalar sağlayarak onların yaşam kalitelerini artırmayı amaçlamaktadır. Müşterilerin psikolojik ve fizyolojik refahını artırmak bu faydaların başında gelmektedir. Bireylerin yaşının ilerlemesiyle birlikte düşen yaşam kalitesi psikolojik, sosyolojik ve gerontolojik olarak ele alınmaktadır. 2050 yılına gelindiğinde 65 yaş üzeri bireylerin dünya nüfusunun \%26'sinı oluşturacağı öngörüsü ile turizm sektöründe potansiyeli yüksek bir pazar olarak ileri yaşlı bireylere odaklanılmaktadır. Yaşam kalitesini artırmak isteyen ileri yaşlı bireylerin emeklilik nedeniyle boş zamanlarının fazla olması, sağlıkları için termal turizmine yönelmesi ve sunulan hizmetleri satın alma gücüne sahip olması işletmelerin bunu bir firsat olarak görüp bu alana yatırım yapmasına neden olmaktadır. Bu bağlamda Kim vd. (2015) ve Sirgy vd. (2012)'nin çalışmaları ile benzer sonuçlara ulaşılmıştır. 
Termal turizmde müşterilerin sağlık durumlarının iyileşmesi ile memnuniyet ve sadakat duygularının da geliştiği araştırmada da desteklenmiştir. Düşük gelirli, kronik rahatsızlıkları bulunan veya dezavantajlı bireyler de dahil olmak üzere toplumun her kesiminden çalışan ve emekli müşteriler termal turizmden yararlanmaktadır. Araştırmaya katılan bireyler incelendiğinde (veri toplama aşamasında katılımcllar tarafından sözlü olarak da ifade edilmiştir) benzer sonuçlara ulaşıldığ görülmüştür. Bu bağlamda Chen ve Petrick (2013)'in çalışması ile benzer sonuçlara ulaşılmıştır. Ayrıca termal turizmde müşterinin destinasyona ulaşmak için sarf ettiği çaba, harcadığı zaman ile katlandığı maliyet müşterinin memnuniyetini ve sadakatini etkilemektedir. Afyonkarahisar'ın lokasyonu nedeniyle avantajlı olduğu sonucuna ulaşılmış olup Tokarchuk vd. (2015)'nin çalışması ile de benzer sonuçlara ulaşılmıştır.

Analiz sonuçları değerlendirildiğinde tüm hipotezlerin kabul edildiği görülmektedir. Gerek basit regresyon analizleri gerekse de aracı etki analizleri sonucu anlamlılık değerlerinin 0,05 'ten az $(p=0,000<0,05)$ olduğu sonucuna ulaşılmıştır. Bu nedenle termal turizm deneyiminin müşteri sadakatine etkisinin olduğu; yaşam kalitesi ve müşteri memnuniyetinin de aracı rolünün olduğu anlaşılmıştır.

Bütçe ve zaman kısıtı nedeniyle araştırma verileri 1-31 Ocak 2021 tarihleri arasında online olarak toplanmış olup 216 veriye ulaşılmıştır. Veri toplama aşamasında katılımcılar, ebeveynlerinin sağlıkları için bu turizm türünü ve Afyonkarahisar'1 tercih ettiklerini ifade etmiştir. Termal turizmi tercih eden bu bireylerin ileri yaşlı bireyler (ve aileleri) olması gelecekteki çalışmalarda dikkate alınabilir. Daha uzun bir zaman diliminde, daha fazla katılımla yüzyüze anketler ile verilere ulaşılabilir. Ayrıca nitel çalışmalar yapılarak (derinlemesine mülakatlar ile) daha fazla bilgi de elde edilebilir.

\section{Açıklamalar}

- Şırnak Üniversitesi Etik Kurulu Başkanlığg'nın 31.12.2020 tarih ve 2020/69 sayılı kararı sonucuna göre çalışma etik yönden uygun bulunmuştur.

- Yazarlar arasında çlkar çatışması bulunmamakta olup çalışmaya katkıları eşittir 


\section{EXTENDED ABSTRACT}

\section{The Mediating Role of Quality of Life and Customer Satisfaction in the Effect of Thermal Tourism Experience on Customer Loyalty: The Case of Afyonkarahisar \\ *}

Osman Özdemir - Burhan Sevim

Şırnak University - Kastamonu University

While tourism is based on visiting and seeing a different destination and spending time there, it has gained a new dimension today and includes tourists having new experiences there. Experience is a current need and desire that customers who want to experience unique and unforgettable moments in the tourism sector expect from businesses, and it is also important in thermal tourism. In this context, businesses can offer experience to their customers by making use of sensory, emotional, cognitive, behavioral and relational experiences. Evaluation of the general condition of individuals in a particular society gives the quality of life. Being emotionally happy; being psychologically stress-free; being physically healthy; socially having family and friends; education and income levels with an objective assessment; with a subjective evaluation, the evaluations of individuals about their lives reveal the quality of life. Customer satisfaction, on the other hand, is the experience that affects the lives of customers as a result of the activities of the enterprises, and it means that they spend quality time.

The aim of this research is to examine the effect of thermal tourism experience on customer loyalty by filling the gap in the literature on the subject of thermal tourism experience. It also evaluates the mediating role of quality of life and customer satisfaction. In this context, the research questions are stated below.

- Does the thermal tourism experience have an impact on customer loyalty?

- Does quality of life and customer satisfaction have a mediating role in the relationship between thermal tourism experience and customer loyalty? 
In this study examining the effect of thermal tourism experience on customer loyalty; thermal tourism experience is included as independent variable, customer loyalty is included as dependent variable, quality of life and customer satisfaction are included as mediating variables in the model. In the research, first of all, a detailed literature review and interviews with academicians were carried out, and a questionnaire form suitable for the model of the research was prepared. Luo et al. (2018)'s study was used for the thermal tourism experience scale; Campón-Cerro et al. (2020)'s study was used for the quality of life scale; Durmuş et al. (2020)'s study was used for the customer satisfaction scale; Mechinda et al. (2009)'s study was used for the customer loyalty scale in the research.

After the result of the decision of Şırnak University Ethics Committee dated 31.12.2020 and numbered 2020/69, the research data were collected online between 1-31 January 2021. Then, data were obtained from individuals who received tourism service from the thermal facilities in Afyonkarahisar. Quantitative analyzes were carried out using Excel, SPSS 23.0 and AMOS 22.0 package programs.

According to the demographic findings of 216 participants in the study, it is seen that women by gender, singles by marital status, those between the ages of 26-35 by age, and university graduates by education level are in the majority. On the sectoral basis, the majority of the 216 participants work in the public and private sectors. In terms of income, it is seen that the rate of those with an income below 5001 TL is high.

Simple Regression Analyzes were performed to test the hypotheses. The hypotheses were accepted based on the result that the significance values were less than $0.05(p=0.000<0.05)$ and are shown Table 1 .

Table 1. Hypothesis Results

\begin{tabular}{|c|c|c|c|c|c|c|}
\hline \multirow[t]{2}{*}{ Hypotheses } & \multirow[t]{2}{*}{$\mathbf{R}$} & \multirow[t]{2}{*}{$\mathbf{R}^{2}$} & $\mathbf{F}$ & \multirow[t]{2}{*}{ B } & $t$ & \multirow[t]{2}{*}{ Result } \\
\hline & & & $p$ & & $p$ & \\
\hline Experience $\rightarrow$ Quality of Life & $0,906^{\mathrm{a}}$ & 0,670 & $\begin{array}{l}437,440 \\
, 000\end{array}$ & 0,819 & $\begin{array}{l}20,915 \\
, 000\end{array}$ & Accept \\
\hline Experience $\rightarrow$ C. Satisfaction & $0,937^{\mathrm{a}}$ & 0,837 & $\begin{array}{l}1103,437 \\
, 000\end{array}$ & 0,915 & $\begin{array}{l}33,218 \\
, 000\end{array}$ & Accept \\
\hline Experience $\rightarrow$ C. Loyalty & $0,868^{\mathrm{a}}$ & 0,753 & $\begin{array}{l}652,971 \\
, 000\end{array}$ & 0,868 & $\begin{array}{l}25,553 \\
, 000\end{array}$ & Accept \\
\hline Quality of Life $\rightarrow$ C. Loyalty & $0,906^{\mathrm{a}}$ & 0,821 & $\begin{array}{l}984,571 \\
, 000\end{array}$ & 0,906 & $\begin{array}{l}31,378 \\
, 000\end{array}$ & Accept \\
\hline C. Satisfaction $\rightarrow$ C. Loyalty & $0,937^{a}$ & 0,877 & $\begin{array}{l}1540,384 \\
, 000\end{array}$ & 0,937 & $\begin{array}{l}39,248 \\
, 000\end{array}$ & Accept \\
\hline
\end{tabular}


Then, mediator effect analyzes were carried out with the Hayes process extension in the SPSS package program and results are shown Table 2.

Table 2. Hypothesis Results for the Mediation Effect

\begin{tabular}{|c|c|c|c|c|c|c|c|}
\hline \multirow[t]{2}{*}{ Hypotheses } & \multirow[t]{2}{*}{ Beta } & \multirow[t]{2}{*}{ se } & \multirow[t]{2}{*}{ LLCI } & \multirow[t]{2}{*}{ ULCI } & \multirow{2}{*}{$\begin{array}{l}\mathrm{t} \\
\mathrm{p}\end{array}$} & \multirow{2}{*}{$\begin{array}{l}R^{2} \\
p\end{array}$} & \multirow[t]{2}{*}{ Result } \\
\hline & & & & & & & \\
\hline Experience $\rightarrow$ C. Loyalty & 0,922 & 0,036 & 0,8511 & 0,9933 & $\begin{array}{l}25,5533 \\
000\end{array}$ & $\begin{array}{l}0,753 \\
, 000\end{array}$ & Accept \\
\hline Exp. $\rightarrow$ Q. L. $\rightarrow$ C. L. & 0,357 & 0,046 & 0,2658 & 0,4482 & $\begin{array}{l}7,7171 \\
, 000\end{array}$ & $\begin{array}{l}0,905 \\
, 000\end{array}$ & Accept \\
\hline Exp. $\rightarrow$ C.S. $\rightarrow$ C. L. & 0,590 & 0,065 & 0,4613 & 0,7202 & $\begin{array}{l}8,9948 \\
, 000\end{array}$ & $\begin{array}{l}0,905 \\
, 000\end{array}$ & Accept \\
\hline
\end{tabular}

It is understood from the changes in Beta value in Table 2 that quality of life and customer satisfaction have a partial mediating role in the effect of experience on customer loyalty. With the mediation effect, Beta values (Beta $=0.357<$ Beta $=0.922)($ Beta $=0.590<$ Beta $=0.922)$ decreased and the hypotheses were accepted.

As a result, thermal tourism aims to increase the psychological and physiological quality of life of customers. Individuals also want to increase their quality of life. They have a lot of free time, prefer thermal tourism for their health and have the power to buy these services. Therefore, businesses to see this as an opportunity and invest in this field. In this context, were reached similar results with Kim et al. (2015) and Sirgy et al. (2012). Therefore, future research can be applied in different time, region and with more participants to cover the whole country. It is expected to contribute to the literature.

\section{Kaynakça / References}

Campón-Cerro, A. M., Di-Clemente, E., Hernández-Mogollón, J. M. and Folgado-Fernández, J.A. (2020). Healthy water-based tourism experiences: Their contribution to quality of life, satisfaction and loyalty. International Journal of Environmental and Research Public Health, 17, 1961.

Chen, C.C. and Petrick, J. F. (2013). Health and wellness benefits of travel experienes: A literature review. Journal of Travel Research, 52(6), 709-719. 
Durmuş E. N. İ., Tanrısever C. ve Pamukçu H. (2020). UNESCO adayı Mahmutbey Camii'ne gelen ziyaretçilerin camiye ve şehre yönelik alg1 ve memnuniyetleri. Gümüşhane Üniversitesi Sosyal Bilimler Enstitüsü Elektronik Dergisi, 11(2), 348-369.

Garnier, S. and Scott, N. (2018). Destination innovation matrix: A framework for new tourism experience and market development. Journal of Destination Marketing $\mathcal{E}$ Management, 10, 122-131.

Hair F. J., Black C. W., Babin J. B., Anderson E. R. andTatham L. R. (2006). Multivariate data analysis. Upper Saddle River, NJ: Prentice Hall Inc.

Johnson, R. and Kong, X. (2011). The customer experience: A road-map for improvement. Managing Service Quality, 21(1), 5-24.

Kim, H., Woo, E. and Uysal, M. (2015) Tourism experience and quality of life among elderly tourists. Tourism Management, 46, 465-476., https://doi.org/10.1016/j.tourman.2014.08.002.

Luo, Y., Lanlung, C., Kim, E., Tang, L. T. and Song, S. M. (2018). Towards quality of life: The effects of the wellness tourism experience. Journal of Travel E Tourism Marketing, 35(4), 410-424, https://doi.org/10.1080/10548408.2017.1358236.

Mechinda, P., Serirat, S. and Gulid, N. (2009). An examination of tourists' attitudinal and behavioral loyalty: Comparison between domestic and international tourists. Journal Vacation Marketing, 15, 129-148.

Özdemir, O. ve Erdem, Ş. (2017). The relationship between experiential marketing and corporate reputation: A research on Turkish operator companies. European Journal of Interdisciplinary Studies, 4(7), 7-14, https://doi.org/10.26417/ejis.v4i2a.p7-14.

Pine, B. J. and Gilmore, J. H. (1999). The experience economy: Work is theatre E every business a stage. Brighton: Harvard Business Press.

Schmitt, B. (1999). Experiential marketing. Journal of Marketing Management, 15(1-3), 53-67.

Sharma, S., 1996. Applied multivariate techniques. New York: John Wiley and Sons Inc.

Shaun, S. and Wheeler, J. (2002). Managing the customer experience: Turning customers into advocates. New Jersey: Financial Times Prentice Hall.

Shaw, C. and Ivens, J. (2002). Building great customer experiences. New York: Palgrave Macmillan.

Sirgy, M.J., Kruger, P.S., Lee, D.J. and Yu, G.B. (2012). How does a travel trip affect tourists' life satisfaction? Journal Travel Research, 50, 261-275, https://doi.org/10.1177/0047287510362784. 
Stamboulis, Y. and Skayannes, P. (2003). Innovation strategies and technology for experience-based tourism. Tourism Management, 24, 35-43.

Tavakol, M. and Dennick, R. (2011). Making sense of Cronbach's Alpha. International Journal of Medical Education, 2, 53-55.

Tokarchuk, O., Maurer, O. and Bosnjak, M. (2015). Tourism experience at destination and quality of life enhancement: A case for comprehensive congruity model. Applied Research Quality Life, 10, 599-613. https://doi.org/10.1007/s11482-0149342-2.

Tümer Karadayı, E. and Koçak Alan, A. (2014). Deneyimsel pazarlama: Pazarlamadaki artan önemi. İsletme Araştırmalar Dergisi, 6(1), 203-217.

Yatırım ve İşletmeler Genel Müdürlüğü, Tesis İstatistikleri. $h$ ttps://yigm.ktb.gov.tr/TR201136/turizm-yatirim-ve-isletme-bakanlik-belgeli-tesis-istati-html. Erişim Tarihi: 14.02.2021

\section{Kaynakça Bilgisi / Citation Information}

Özdemir, O. ve Sevim, B. (2021). Termal turizm deneyiminin müşteri sadakatine etkisinde yaşam kalitesi ve müşteri memnuniyetinin aracı rolü: Afyonkarahisar örneği. OPUS-Uluslararası Toplum Araştırmaları Dergisi, 18(41), 3609-3630. DOI: 10.26466/ opus. 925920 . 